\title{
POLÍTICA DO OLHAR E COMUNIDADE DE SENTIDOS NAS REPRESENTAÇÕES FOTOGRÁFICAS DE UMA “ÁFRICA PORTUGUESA" (1960-1970)
}

\author{
POLICY OF LOOKING AND COMMUNITY OF SENSES IN \\ PHOTOGRAPHIC REPRESENTATIONS OF A "PORTUGUESE \\ AFRICA" (1960-1970)
}

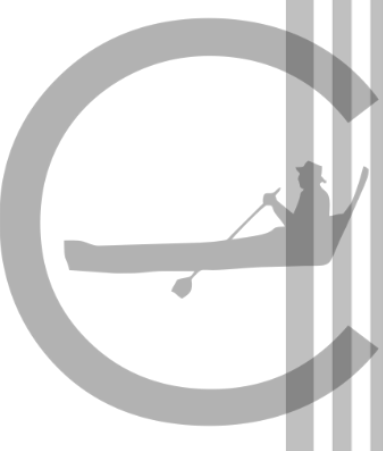

Harley Abrantes Moreira'

\begin{abstract}
Resumo
Esse artigo trata da linguagem fotográfica. Seu objeto é um conjunto de fotografias, supostamente de africanos (a), publicadas por uma revista missionária brasileira durante a década de 1960. Através dos conceitos de "representação", nos termos elaborados por Roger Chartier, e de "comunidade de sentidos", segundo Michel Foucault, perseguiremos o duplo objetivo de mostrar o funcionamento dessas imagens enquanto vetores de comunicação cultural e demonstrar que, mesmo sem as informações autorais relevantes para a sua análise, é possível, ao historiador, seguir as pistas que apontem para suas provisórias conclusões, aqui denotadas pela afirmação de que tais imagens participavam de um circuito de formação de sentidos, onde portugueses e brasileiros compartilhavam de ligações simbólicas, com as quais a África e seus habitantes eram construídos e dados a ler.
\end{abstract}

Palavras-chave: História; África; fotografias.

\begin{abstract}
This article deals with the photographic language. Its object is a set of photographs, supposedly of Africans, published by a Brazilian missionary magazine during the 1960s. Through the concepts of "representation", in the terms elaborated by Roger Chartier, and of "community of senses", according to Michel Foucault, we will pursue the dual objective of showing the functioning of these images as vectors of cultural communication and demonstrating that, even without the relevant copyright information for their analysis, it is possible for the historian to follow the clues that point to his provisional conclusions, here denoted by the affirmation that such images participated in a circuit of formation of meanings, where Portuguese and Brazilians shared symbolic connections, with which Africa and its inhabitants were constructed and given to read.
\end{abstract}

Keywords: History; Africa; photographs.

\section{Introdução}

\footnotetext{
${ }^{1}$ Professor adjunto da Universidade de Pernambuco (UPE). E-mail: harleyabrantes@ hotmail.com
} 
O imperialismo cultural e o colonialismo português foram notáveis pela persistência e pela longevidade que atingiram. No momento em que esses processos se enfraqueciam entre as potências europeias que perdiam suas colônias em África, o estado totalitário português, estruturado nas colunas do Estado Novo (1933-1974), ampliava e consolidava suas redes de controle nos mundos luso-africanos do pós Segunda Guerra Mundial. Durante esse período, na década de 1960, uma revista missionária brasileira dialogava com o mundo português e começava a publicar fotografias das colônias lusoafricanas, para onde os cristãos batistas brasileiros almejavam enviar seus missionários.

A Revista $O$ Campo é o Mundo foi criada em 1955 com a finalidade de divulgar notícias sobre as missões batistas brasileiras em outros países através de variados materiais que visavam "a conscientização dos fiéis quanto a necessidade de investimentos" e orações. Esses apelos eram abundantemente imagéticos e a linguagem fotográfica foi fartamente utilizada por esse periódico. Vale salientar que, ainda que produzida no Brasil pela Junta de Missões Mundiais (JMM), uma agência missionária brasileira desse grupo, a revista publicava matérias escritas por batistas portugueses e anteriormente publicadas em seus próprios instrumentos midiáticos estabelecidos em territórios lusitanos.

Para uma compreensão adequada das análises a serem realizadas, também é importante frisar que, na década de 1960, onde se situam as fotografias investigadas nesse artigo, ainda não havia brasileiros enviados pelas instituições nacionais dessa denominação religiosa que então se preparava para o envio de seus primeiros missionários, o que só viria a concretizar-se no início da década seguinte, quando o grupo brasileiro que então se capacitava nos Seminários Batistas de Recife e do Rio de Janeiro, chegaria, finalmente, em Moçambique e em Angola, as únicas colônias a receberem enviados dessa agremiação no Brasil.

Fazia parte dessa preparação institucional, divulgar diversas notícias, textos e fotografias do continente africano nas páginas da revista. Essas matérias que não eram produzidas pelos brasileiros, e sim pelos portugueses que já tinham seus representantes estabelecidos em suas colônias desde a década de 1950 (e com os brasileiros mantinham comunicação assídua), eram novamente publicadas no Brasil, em um circuito de "trocas de

\footnotetext{
${ }^{2}$ MOREIRA, Harley Abrantes. Missões Batistas em Angola e Moçambique no Período de Descolonização: apontamentos para uma discussão do discurso da revista O Campo é o Mundo. Sankofa - Revista de História da África e de Estudos da Diáspora Africana. São Paulo: Ano VII, nº XIII, Julho/2014. p.4.
} 
correspondências e textos" ${ }^{3}$ envolvido em um processo de construção imagética do Outro, alicerçado em representações repletas de estereótipos africanos que podem ser percebidos em conjuntos de imagens e na parceria que formavam com os textos que lhes acompanhavam.

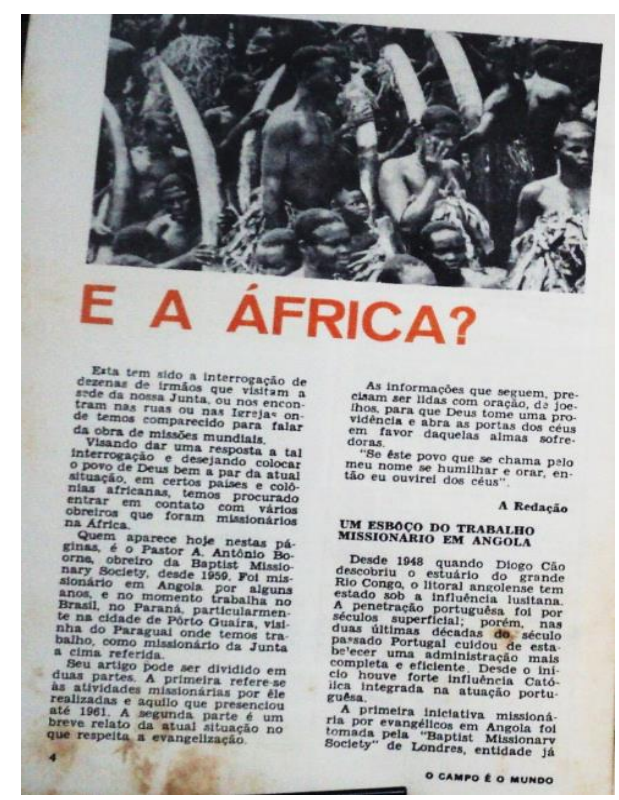

Imagem 1: Fotografia sem referência de autor, data e contexto. Localizada na página 4 da revista O Campo é o Mundo, $\mathrm{n}^{\circ}$ 4, 1966. Na posição superior da página a qual apresenta um texto cujo título é: "E a África?"

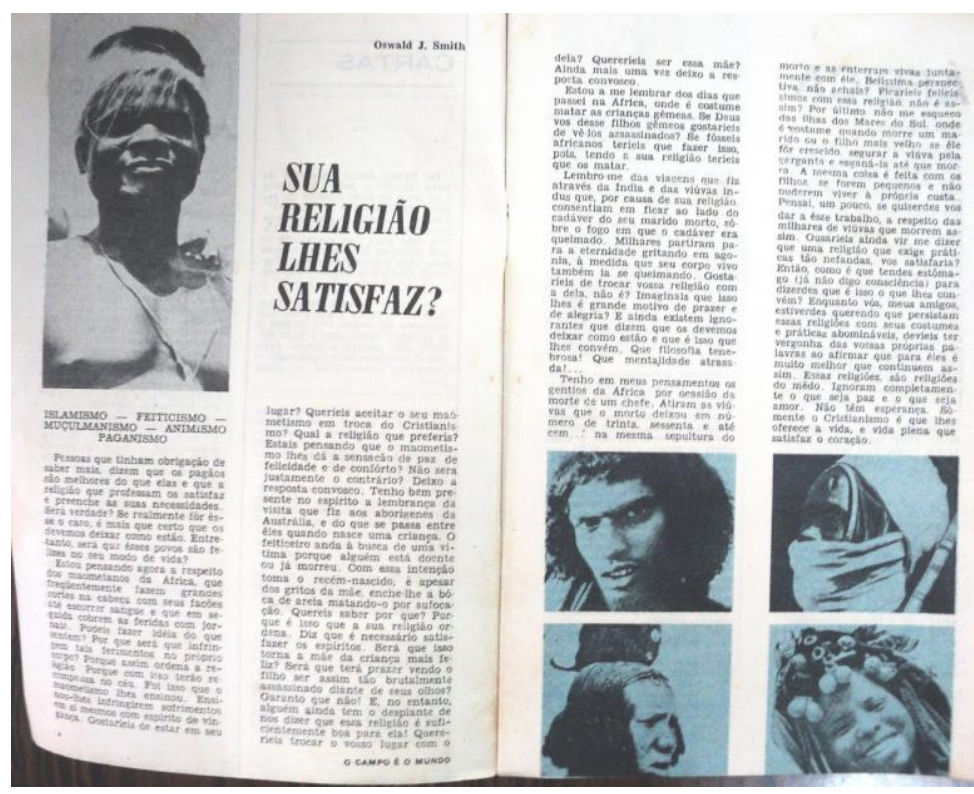

Imagem 2: Fotografia sem referência de autor, data e contexto. Localizada na página 4 da revista O Campo é o Mundo, nº, 1967, no canto superior esquerdo, acima de um texto cujo título era: "Sua Religião lhe satisfaz?".

${ }^{3}$ MOREIRA, Harley Abrantes. "Onde há desespero, a esperança é importante”? Uma história da expansão do cristianismo batista em Moçambique (1950-1992). Tese de Doutorado em História cultural, Instituto de Filosofia e Ciências Humanas, Universidade de Campinas, Campinas, 2019. p.77. 


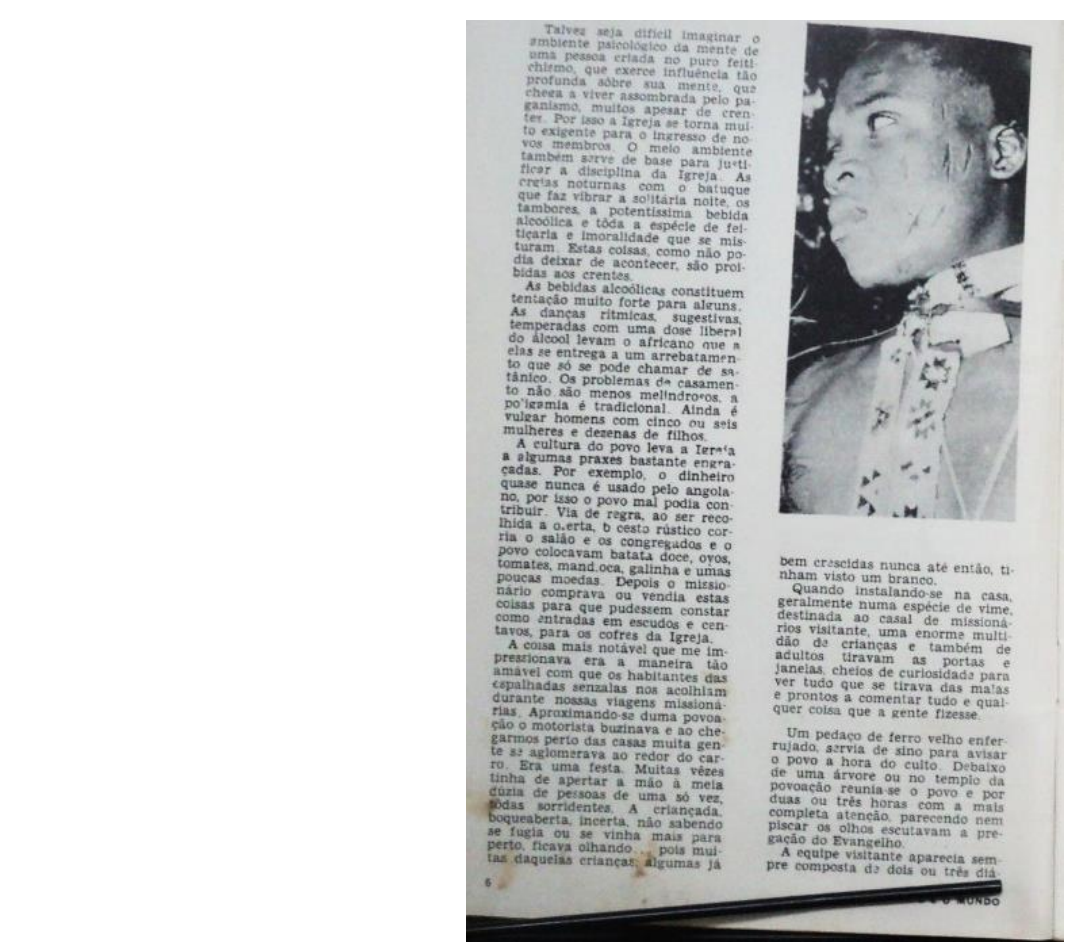

Imagem 3: Fotografia sem referência de autor, data e contexto. Localizada na página 7 da revista O Campo é o Mundo, $\mathrm{n}^{\circ} 4,1966$. Ainda integrada ao mesmo texto da fotografia $\mathrm{n}^{\circ} 1$.

As diversas imagens exibidas pela revista constituem um material documental peculiar na medida em que o funcionamento de uma fotografia é diferente de um texto que, sabemos, pode evocar diferentes interpretações, no entanto, as imagens fotográficas são notavelmente polissêmicas e nunca possuem apenas um significado. Inseri-las em um corpus documental significa abrir um leque de questionamentos, além de testar variadas possibilidades. Em nosso caso, o fato de na década de 1960 não existirem missionários brasileiros batistas na África torna-as ainda mais intrigantes... Quem fotografou aqueles rostos e corpos negros? Onde? Por que tais preferências e tais enquadramentos? Quando foram tiradas e, ainda, como foram parar ali nas páginas da Revista $O$ campo é o Mundo? As desinformações quanto à autoria indicam, necessariamente, a inviabilidade da pesquisa historiográfica com essas fontes?

O longo percurso histórico que introduziu a documentação fotográfica no hall de fontes disponíveis ao trabalho do historiador apresenta apontamentos importantes para a abordagem desse inventário de interrogações. Desde o século XIX, quando ainda era grande a resistência à utilização historiográfica de qualquer material não escrito, passando pelas vanguardas da escola metódica que teriam considerado o uso das fotografias pelo historiador (desde que estivessem hierarquicamente sobrepostas à documentação textual), até os diálogos interdisciplinares mais recentes que muniriam os historiadores de múltiplos 
questionamentos necessários ao trabalho com fontes fotográficas, um longo percurso foi percorrido ${ }^{4}$.

Como resultado desse amadurecimento, a ideia de que a fotografia, em si, não é a única responsável pela construção dos sentidos da imagem que apresenta, parece contribuir com o manejo menos ingênuo que, hoje, historiadores (a) possam fazer dessas fontes documentais. Ana Maria Mauad indica que, mais que a intenção do fotógrafo ao enquadrar, decidir, editar sua foto, os leitores da fotografia precisam ser ainda mais considerados, uma vez que é dentro de seus mundos culturais que essas imagens serão compreendidas e significadas. Para a autora:

É a competência de quem olha que fornece significados à imagem. Essa compreensão se dá a partir de regras culturais, que fornecem a garantia para que a leitura da imagem não se limite a um sujeito individual, mas que acima de tudo seja coletiva. Na qualidade de destinatário da mensagem fotográfica, ele [o leitor] detém uma série de saberes que envolvem outros textos sociais. ${ }^{5}$

Assim, ao trabalhar com documentos fotográficos, o historiador não pode esquecer que não é objeto de seu "máximo" interesse a tarefa de analisar tecnicamente e de forma exaustiva os aspectos formais desses materiais, entre os quais o questionário de interrogações dirigidas aos fotógrafos. Embora o lugar social e o repertório técnico deste sejam muito importantes, o historiador precisa apontar para os canais de comunicação, construídos mediante a códigos culturais, melhor decifrados se considerados dentro dos diálogos que as imagens compunham com textos, músicas, edifícios, literaturas ou qualquer outro tipo de fonte bibliográfica e documental com a qual essas fotografias se comunicassem.

Uma importante lista de questionamentos sobre o fotógrafo, afim de compreender seus enquadramentos dentro de um tempo histórico e um lugar social, não será, portanto, realizada nesse texto, uma vez que as interrogações dirigidas a autoria das fotos não podem

\footnotetext{
${ }^{4}$ ABOUT, Ilsen \& CHÉROUX, Clement. L'histoire par la photographie. Revista Études photographiques, Société Française de Photographie, Paris: nov. n.10, 2001. p.1-20; BORGES, Maria Eliza Linhares. História e Fotografia. Belo Horizonte-MG: Ed. Autêntica, 2013. p.24-35; CANABARRO, Ivo. Fotografia, história e cultura fotográfica: aproximações. Estudos Ibero-americanos, v.31, 2, $2006 . \quad$ p.23-39. https://doi.org/10.15448/1980-864X.2005.2.1336; CANABARRO, Ivo Santos. Fotografa e História: questões teóricas e metodológicas. Revista Visualidades, Goiânia, v.13, n.1, jan-jun 2015. p.98-125; CARVALHO, Vânia Carneiro de \& LIMA, Solange Ferraz de. Fotografias: usos sociais e historiográficos. In: $O$ historiador e suas fontes. Ed. Contexto, São Paulo, 2009. p.29-60; DUBOIS, Philippe. O ato fotográfico e outros ensaios. Campinas: Papirus, 1994. p.25-27; KOSSOY, Boris. Fotografia e História. São Paulo: ed. Ateliê, 2003; p.1964.

${ }^{5}$ MAUAD, Ana Maria. Na mira do olhar: um exercício de análise da fotografia nas revistas ilustradas cariocas, na primeira metade do século XX. Anais do Museu Paulista. São Paulo: n.1, v.13, jan.-jun. 2005. p.142.
} 
ser respondidas porque o periódico não oferecia qualquer dado autoral a respeito das fotos que publicava.

No entanto, através desse material, podemos identificar elementos que compõem padrões visuais em funcionamento dentro da comunidade de sentido ${ }^{6}$ composta pelo amplo conjunto de igrejas e instituições, às quais essas fotos eram endereçadas e circulavam dentro de um circuito de cooperações entre batistas brasileiros e portugueses. A percepção do que significava a linguagem fotográfica colonial do período, seu alcance, sua utilização e circulação no mundo de língua portuguesa de então, somada ao repertório cultural dos leitores da revista onde nossas imagens eram publicadas, no Brasil, é o que nos permitirá a elaboração de possibilidades com razoável margem de segurança.

\section{Brasil e Portugal: a circulação de impressos e pessoas}

Primeiro, é preciso explicar que, ao publicar essas fotos, a imprensa batista brasileira tomava parte de uma cultura visual ocidental, dentro da qual a tecnologia fotográfica encontrava-se em expansão ${ }^{7}$ e, no contexto da Revista $O$ Campo é o Mundo, atuava como importante parte integrante da mensagem que se queria transmitir a partir do sentido que as imagens construíam. Apesar de desconhecermos a autoria daquelas fotografias exploradas pelo periódico, sabemos que diversos textos publicados primeiramente pela mídia batista portuguesa eram aproveitados pela revista brasileira que, pela segunda vez, os publicava. Uma prática que ocorria com mais frequência durante a década de 1960, período em que a Convenção Batista Brasileira ainda não tinha representantes na África e, por isso, precisava divulgar matérias elaboradas em Portugal que, desde 1950, já contava com uma igreja e uma equipe de missionários em colônias como Moçambique $^{8}$.

Dessa forma, há indícios de que as imagens sem autoria expostas na revista brasileira tenham sua origem nos periódicos batistas portugueses, ou mesmo em um circuito lusófono de fotografias coloniais, dentro do qual estes se comunicariam. A reprodução direta

\footnotetext{
${ }^{6}$ Utilizo o termo no sentido aplicado por Michel Foucault, no livro "A arqueologia do saber", no qual a comunidade de sentido relaciona-se às ligações simbólicas e ao jogo de semelhança e de espelho em que a soberania de uma consciência coletiva surge como princípio de unidade. FOUCAULT, Michel. A arquelogia do saber. $5^{\mathrm{a}} \mathrm{ed}$, Rio de Janeiro: Forense Universitária,1997. p.24.

${ }^{7}$ VICENTE, F. O Império da visão: histórias de um livro. In: O Império da visão: fotografia no contexto colonial português (1860-1960). Lisboa: ed. Edições 70, 2014, p.11-30.

${ }^{8}$ Vários trechos desses textos podem ser encontrados na tese doutoral “Onde há desespero, a esperança é importante"? Uma história da expansão do cristianismo batista em Moçambique (1950-1992). Essas matérias indicam, na própria revista, sua anterior publicação pelo jornal batista português $O$ Semeador. Ver: MOREIRA, Harley, Abrantes. "Onde há desespero, a esperança é importante"? Uma história da expansão do cristianismo batista em Moçambique (1950-1992). Tese de Doutorado em História cultural, Instituto de Filosofia e Ciências Humanas, Universidade de Campinas, Campinas, 2019, p.54 à 104.
} 
e pré-concebida do continente africano e de seus habitantes revelava também a existência de uma comunhão com determinado imaginário ocidental que, àquela altura, já fazia parte de uma extensa tradição de elaboração de representações sobre a África, da qual o periódico se valia para, ao republicar materiais oriundos de outros canais do mundo lusitano, atingir a comunicação necessária e dar continuidade ao objetivo de informar e sensibilizar os batistas brasileiros, fazendo-os compreender a importância das missões, motivando-os a cooperar com a abertura futura desse novo campo missionário do qual também deveriam participar, sentindo-se por ele responsáveis.

Uma vez que, naquele momento, ainda não havia, em África, pastores, correspondentes ou, muito menos, fotógrafos enviados pelos batistas brasileiros, o elo desse grupo era, justamente, os religiosos portugueses com os quais, há várias décadas, construíam sólidos laços de trocas culturais, em um trânsito "transnacional" que fazia circular os impressos daquela denominação, suas representações e apropriações construídas nesse fluxo $^{9}$ que envolvia cooperações de diversas naturezas e um intercâmbio entre batistas brasileiros e portugueses com décadas de existência.

As primeiras movimentações missionárias internacionais propagadas por batistas brasileiros dirigiram-se justamente à nação lusitana e remontam ao começo do século XX. Desde então, as trocas de correspondências e textos eram republicadas nos impressos das convenções batistas brasileira e portuguesa. Na década de sessenta, cinquenta eram as igrejas conduzidas por trinta pastores nacionais espalhados em território português. Esse crescimento e estabilização era atribuído ao esforço e apoio dos brasileiros que, desde 1908, atuaram no envio de missionários para Portugal, primeiro e principal país a receber a atenção da, então, Junta de Missões Estrangeiras ${ }^{10}$.

\footnotetext{
${ }^{9} \mathrm{~A}$ ideia de transnacionalidade pode ser aplicada a situações em que eventos ou processos envolvendo sujeitos históricos ocorrem mediante relações em espaços dilatados, onde a nacionalidade dos agentes é de pouca utilidade para compreendê-los. Ver: ROCHA, Cristina. O Brasil na nova cartografia global da religião. Revista Religião e Sociedade, Rio de Janeiro: vol.34, nº1, junho de 2014. p.22 e ROCHA e VÁSQUEZ. A diáspora das religiões brasileiras. Ed. Ideias e letras, São Paulo, 2016. p.326. No caso das relações entre batistas brasileiros e portugueses, mais que interações físicas e concretas, as comunidades transnacionais podiam ser compostas por indivíduos que não conviviam no mesmo país e, ainda assim, se conectavam através de práticas culturais. Por sua vez, o conceito de "fluxo", desde o final dos anos noventa já se tornou transdisciplinar e vem sendo usado como um modo de fazer referência às coisas que não permanecem no mesmo lugar, a mobilidades e expansões variadas. Ver: HANNERZ, U. Fluxos, fronteiras, híbridos: palavras-chave da antropologia transnacional. In: Revista Mana, Rio de Janeiro, n ${ }^{\text {o }}$, vol. 1, 1997. p.7-39. Assim, durante a primeira metade do século XX, as relações entre batistas brasileiros e portugueses ocorriam em um fluxo transnacional que lhes caracterizava como um espaço supranacional de práticas culturais.

${ }^{10}$ Segundo o periódico, logo em seguida à criação da Convenção Batista Brasileira (CBB), em 1907, e com cerca de 4.000 membros espalhados pelo país, foi fundada, no ano seguinte, a Junta de Missões Estrangeiras, filiada à CBB. No mesmo ano, os primeiros missionários foram enviados a Portugal, onde fundaram a primeira igreja batista em solo português, localizada na cidade do Porto. Cf: Biblioteca do Seminário de Educadoras
} 
A circulação que caracterizava as relações batistas dos dois países era intensa. Cidades como Leiria, atraíam a atenção dos batistas brasileiros em razão da devoção à Fátima. Lisboa, capital portuguesa, era uma importante referência onde esse grupo ainda desejava penetrar e, por outro lado, a cidade universitária de Coimbra, descrita com pompa por missionários que lá chegaram a partir de 1957, era à altura um importante centro que unia os trabalhos desse grupo religioso dos dois países. ${ }^{11}$

Na década de 1960, o fluxo e a comunicação entre batistas brasileiros e portugueses era constante e, segundo os títulos de algumas matérias publicadas pela revista, "evangelizar o Brasil é evangelizar Portugal”, assim dizia Antônio Maurício, um missionário português, nascido na cidade de Viseu, de onde, em 1919, partira, ainda jovem, rumo ao Rio de Janeiro, para estudar no Seminário Batista da então capital do Brasil. Após concluir seus estudos, foi enviado de volta à sua terra natal e lá mantido pela Junta de Missões Mundiais (JMM) da Convenção Batista Brasileira $(\mathrm{CBB})^{12}$. Essas relações e esses contatos entre batistas portugueses e brasileiros eram construídos, também, através de viagens missionárias e pastorais mais curtas. As viagens de "executivos" das agências missionárias e das convenções batistas eram comuns. Eram usadas para troca de experiências, de informações e para a motivação dos cristãos ao envolvimento com os trabalhos missionários.

Em 1968, o pastor José Leovegildo Soares, presidente da Convenção Batista Portuguesa, a convite da Junta de Missões Estrangeiras do Brasil, visitou o país em temporada que durou três meses. Durante esse tempo esteve em igrejas e convenções espalhadas por nove estados da federação, falando em acampamentos, congressos e diversos eventos. ${ }^{13}$ Dessa forma, as fotografias expostas na Revista $O$ Campo é o Mundo, captadas da mídia impressa portuguesa, precisam ser lidas dentro de um contexto de cooperação e comunicação de brasileiros com portugueses que, há décadas, produziam, recolhiam e expunham as imagens de suas colônias difundidas no mundo lusófono. Essas imagens, por sua vez, não eram uma linguagem utilizada exclusivamente por esses protestantes.

cristãs de Recife. REDAÇÃO. Revista O Campo é o Mundo, 1966, Traços históricos do trabalho batista em Portugal, ed. JUERP, nº 3, p.10.

${ }^{11}$ A igreja de Coimbra era formada por "crentes com altos cargos no comércio, estudantes universitários e dos Liceus". A construção de um "lar acadêmico" era meta dessa comunidade que tinha a intenção de atuar na formação cristã dos futuros médicos, advogados e professores, os quais deveriam espalhar-se por todos os países de Língua Portuguesa, destacando-se as colônias ultramarinas. Cf: Biblioteca do Seminário de Educadoras cristãs de Recife. REDAÇÃO. Revista O Campo é o Mundo, 1967, O clamor de Coimbra, ed. JUERP, nº $8.12-13$.

${ }^{12}$ Cf: Biblioteca do Seminário de Educadoras cristãs de Recife. MAURÍCIO, Antônio. Revista O Campo é o Mundo, 1969. Evangelizar Portugal é evangelizar o Brasil, outubro-dezembro. p.9.

${ }^{13}$ Biblioteca do Seminário de Educadoras cristãs de Recife. REDAÇÃO, Revista O Campo é o Mundo, 1968, Minha visita ao Brasil, ed. JUERP, $\mathrm{n}^{\circ} 10$. p.5. 
Diferentemente, faziam parte de um amplo circuito cultural de políticas imperialistas com cerca um século de formação.

\section{O circuito de fotografias no mundo português}

A fotografia que, na altura, era parte de uma tecnologia em expansão e bastante utilizada pelas nações imperialistas, desde o século XIX, fora utilizada para demonstrar poder sob as extensões coloniais repletas de nativos, considerados pertencentes a uma raça inferior, que precisava ser alcançada pela civilização ocidental, inserida na África por intermédio de seus negócios, suas empresas, seus missionários religiosos ou "científicos". ${ }^{14}$

Através das imagens, esses distantes mundos exóticos se davam a ler e as virtudes da persistência e da coragem ocidentais em se aventurar por lugares tão distantes e inóspitos para cumprir sua missão civilizacional, podiam ser apreciadas em exposições fotográficas coloniais que, em outras potências europeias, vinham sendo utilizadas desde o início do século XX e, em Portugal, foram habilmente manipuladas pela ditadura salazarista, em um circuito cultural que transformou essas fotografias em produtos populares, presentes nas agendas de entretenimento que movimentaram a sociedade portuguesa metropolitana a partir da década de 1930. Segundo James Ryan,

As exposições fotográficas coloniais que expunham nativos e aldeias africanas continuaram até meados do século XX em muitos países europeus, incluindo Portugal. Muitos eventos do gênero foram registrados em postais ilustrados, que em 1900 se tinham tornado no artigo fotográfico mais omnipresente e de circulação de massa e que pôs ao alcance de todas as classes de cidadãos europeus imagens coloniais de culturas distantes. ${ }^{15}$

Apesar das fotografias apresentadas pela Revista nesse período não serem identificadas em suas legendas, é verossímil supor que chegaram ali nas páginas do periódico através das intensas trocas entre os batistas brasileiros e o mundo português acessado através de seus irmãos de fé religiosa. Analisá-las, portanto, significa, também, considerar inseri-las dentro do contexto de produção imagética do mundo colonial português que procurava legitimar-se, dentro e fora de suas fronteiras, mediante a construção de um "império da

\footnotetext{
${ }^{14}$ SANTANA, Noeme. Olhares britânicos: visualizar Lourenço Marques na ótica de J and M Lazarus, (18991908). In: VICENTE, Filipa Lowndes. O Império da visão: fotografia no contexto colonial português (18601960). Lisboa: ed. Edições 70, 2014. p.211-222; VARGAFTIG, Nadia. Para ver, para vender: o papel da imagem fotográfica nas exposições coloniais portuguesas (1929-1940). In: VICENTE, Filipa Lowndes. $O$ império da visão: fotografia no contexto colonial português (1860-1960). Lisboa: ed. Edições 70, 2014. p.343352 ;

${ }^{15}$ RYAN, J. Fotografia colonial. In: VICENTE, F. O Império da visão: fotografia no contexto colonial português (1860-1960). Lisboa: ed. Edições 70, 2014. p.31.
} 
visão”, erguido pelas lentes de seus fotógrafos que costumavam ser administradores, padres e colonos que fizeram da África portuguesa um laboratório de imagens.

Nas páginas da revista, esse material conservou um certo padrão durante a década de 1960, revelando, sempre, africanos tribais, sem camisas, negros, portando adereços artesanais sugerindo seus pertencimentos às culturas tradicionais, estranhas e obscuras para o público das igrejas batistas brasileiras que lia essas mensagens e, junto com essa mídia impressa, construía um sentido para o papel evangelizador da igreja e um significado para o continente africano e seus povos "passivos e receptores".

Essa construção de sentido, apesar de sua natureza religiosa, dialogava com uma cultura imperial mais ampla em diferentes aspectos. Um deles refere-se à desatenção à condição do Outro como sujeito das afirmações sobre sua própria identidade. Na década de sessenta, o que prevalecia era o conteúdo imagético e textual que destacava o africano primitivo, exótico, explorado e passivo. Essas imagens eram as provas definitivas de um sentido científico e até judicial da missão civilizadora em África.

As leis jurídicas portuguesas sofreram modificações que, durante a primeira metade do século XX, formularam um estatuto para consolidar o colonialismo português. Segundo o Acto colonial de 1930, era da "essência orgânica de Portugal desempenhar a função histórica de possuir e colonizar domínios ultramarinos e de civilizar as populações que neles se compreendam"16. Para Omar Ribeiro Thomaz, o Acto Colonial demandava dos portugueses "uma reflexão sobre o lugar de Portugal no mundo e sua missão de possuir e colonizar territórios distantes e incorporar plenamente na "lusa grei" gentes exóticas que, na realidade, seriam verdadeiros portugueses". ${ }^{17}$

A divulgação de fotografias de africanos e africanas que reforçassem os estereótipos coloniais dos povos considerados primitivos visavam comprovar as necessidades das realizações imperiais de Portugal em um momento em que, há um século, as fotografias dos mundos colonizados já circulavam na Europa pelas galerias de exposições que passaram a ocupar a função de opção de lazer e entretenimento para as famílias europeias que, desse modo, tomavam conhecimento da obra civilizacional de suas nações, através de uma linguagem acessível, mesmo aos cidadãos não letrados que, assim, se convenciam de um mundo selvagem, carente das intervenções ocidentais.

\footnotetext{
${ }^{16}$ Acto Colonial, Decreto-Lei no 18570 de 8 de Julho de 1530. Disponível em: https://dre.pt/pesquisa//search/224055/details/maximized. Consultado em 11 de setembro de 2020.

17 THOMAZ, Omar Ribeiro. Ecos do Atlântico Sul: Representações Sobre o Terceiro Império Português. Ed. UFRJ, Rio de Janeiro, 2002, p. 80.
} 
Tratava-se de um mundo completamente desconhecido para os batistas brasileiros que não contavam com seus próprios correspondentes nas colônias portuguesas em África. A divulgação dessas fotografias nas páginas da revista brasileira, portanto, era essencial para que essas realidades dos territórios luso-africanos fosse apresentada, no Brasil, por aquelas fotografias, provavelmente portuguesas, através das quais aqueles cristãos brasileiros acessavam seus próprios estereótipos da África e dos negros, peculiarmente presentes na história e na memória nacional brasileira, que precisam ser consideradas na tentativa de se compreender a construção histórica dos sentidos dessas imagens.

\section{Os (a) leitores (a) brasileiros (a)}

Ao analisar um conjunto de fotografias de autoria desconhecida, as perguntas, fundamentais no trabalho do historiador, tornam-se ainda mais imprescindíveis. Segundo Natalie Zamon Davis: "Quando não encontramos o homem ou a mulher que estamos procurando, é necessário voltar, na medida do possível, para outras fontes do mesmo tempo e do mesmo lugar, a fim de descobrir o mundo que eles deviam conhecer e as reações que podem ter tido" $"$.

Todavia, apontar para o circuito europeu português de produção e consumo daquelas fotografias não é suficiente para compreender de que modo adentravam e quais seus efeitos entre os leitores daquele periódico religioso no Brasil que, a partir de sua cultura religiosa e de uma memória social nacional poderiam formular diversas apropriações que faziam da apreciação daquelas fotografias uma prática cultural construída no fluxo de comunicação existente entre portugueses e brasileiros daquele grupo religioso. Segundo Roger Chartier,

essas práticas são criadoras de usos ou de representações que não são absolutamente redutíveis às vontades dos produtores de discursos e normas. [...] A aceitação dos modelos e das mensagens propostas operase por meio dos arranjos, dos desvios, às vezes das resistências, que manifestam a singularidade de cada apropriação ${ }^{19}$.

Nesse sentido, é importante levantar possibilidades de leituras dessas imagens que encontravam, no Brasil, um novo público, formado por pessoas que estudavam nas instituições de ensino desse grupo, onde essa literatura era disponibilizada na intenção de formar e informar a liderança religiosa, que poderia ainda divulgar o material também nas igrejas. Em tese defendida em 2013 na Universidade Federal de Uberlândia - MG, Maria

\footnotetext{
${ }^{18}$ GINZBURG, Carlo. Apêndice - Provas e possibilidades. In: O Fio e os Rastros. São Paulo: Ed. Companhia das Letras, 2014. p. 315.

${ }^{19}$ CHARTIER, Roger. Leituras e leitores na França do Antigo Regime. São Paulo: ed. Unesp, 2004, p.13-14.
} 
Lourdes dos Anjos explica que uma das mais fortes bases de atuação dos batistas era a Educação. Escolas anexas, colégios, Escola Bíblica Dominical eram apenas alguns dos projetos que, somados aos institutos de ensino religioso e aos seminários, representavam esse corpo educacional.

Alguns apontamentos encontrados no trabalho da autora merecem ser mencionados como pistas para a compreensão das lentes, através das quais as fotografias dos mundos ultramarinos portugueses poderiam ser interpretadas pelos leitores brasileiros. Os valores patrióticos, a moral rígida e a coerência doutrinária com os princípios da denominação batista eram constantemente afirmados pelas alunas dessas instituições que, diariamente, antes das sete horas da manhã, desciam de suas acomodações, no internato onde residiam, para a solenidade cívica de hasteamento da bandeira brasileira e canto do hino nacional. Havia uma escalação agendada das jovens que se reversavam diariamente na tarefa de hastear o símbolo nacional antes de, juntas, declamarem a canção. As aulas de Civismo e os projetos de apresentações de coral em hospitais militares ou o evangelismo nos quartéis eram laços sólidos e contínuos de uma relação de cooperação mútua, não apenas com o governo militar, mas com seus valores e simbologias notados (a), também, no regime português que antecedeu a Revolução dos Cravos $(1974)^{20}$.

\section{A comunhão de sentidos em um mundo batista luso-brasileiro}

A partir da década de 1930, o Estado Novo português ampliou seus mecanismos de vigilância social, censura, disciplina, tortura e difusão dos valores religiosos mais conservadores, introjetados nos hábitos culturais, comportamentos e cotidiano da população portuguesa que vivia um modelo de ordem social muito próximo dos outros fascismos

\footnotetext{
${ }^{20}$ A respeito da cultura educacional dos Seminários batistas, ver: ANJOS, Maria de Lourdes Porfírio Ramos Trindade dos. Educação feminina batista no Nordeste: a ação educacional de Martha Elizabet Heristhon no Seminário de Educadoras cristãs de Recife (1953-1979). Tese de doutorado em Educação. Programa de Pós Graduação em Educação, Universidade Federal de Uberlândia, 2013. p.195-262; A respeito da "comunhão" simbólica e de valores entre essas instituições e os regimes autoritários português e brasileiro, ver: MOREIRA, Harley. Batistas brasileiros em Moçambique: cultura, política e missionarismo no colonialismo tardio e no pós independência. In: Missões, religião e cultura - Estudos de História entre os séculos XVIII e XX. (Orgs.) MOREIRA, H; MOURA, C. e SILVA, E. Ed. Prismas, Curitiba, 2017. p.350-352; Ver também: SILVA, Paulo Julião. "E Jesus foi vitorioso. Aleluia...E a resposta a essa batalha do céu foi 31 de março de 1964" - O alinhamento protestante ao golpe militar. In: MOURA, Carlos André de; SILVA, Eliane Moura da; SANTOS, Mario; SILVA, Paulo Julião. (Orgs.). Religião, Cultura e Política no Brasil: Perspectivas históricas. IFCH/UNICAMP, Campinas, 2011. E, do mesmo autor: O Anticomunismo Protestante e o Alinhamento ao Golpe Militar. Ed. Prismas, Curitiba, 2014, p.138-152. A documentação primária também é generosa em sinais de cooperação entre os governos militares e as lideranças batistas no Brasil e nas colônias portuguesas em África: Biblioteca do Seminário de Educadoras cristãs de Recife. REDAÇÃO, Revista O Campo é o Mundo, 1968, Fotos que Falam, ed. JUERP, Rio de Janeiro nº 10, p.14; REDAÇÃO, Revista O Campo é o Mundo, 1973, Notícias da África, ed. JUERP, Rio de Janeiro, jan/fev/mar, p.9 e REDAÇÃO, Revista O Campo é o Mundo, 1972, Notícias da África, ed. JUERP, Rio de Janeiro, jan/fev/mar, p.33-35.
} 
europeus, ${ }^{21}$ ainda que com suas próprias características. Segundo Oliveira Marques, era "particularmente objeto da vigilância da censura tudo quanto respeite: a ideia de Pátria, a independência nacional e o prestígio do País, bem como ao respeito devido à bandeira, ao hino nacional e a outros símbolos da Pátria"22.

Esse conjunto de valores cívicos e tradicionais também poderia ser encontrado nas instituições batistas brasileiras. O acompanhamento e a supervisão das alunas do Seminário de Educadoras Cristãs (SEC) e do Instituto Batista de Educação Cristã (IBER), onde circulavam as revistas, se efetuava através de mecanismos muito próximos dessas identificações em torno das ditaduras brasileira e portuguesa se considerarmos que à frente dos institutos de formação missionária havia um mastro com a bandeira nacional, símbolo pátrio sempre presente, não apenas em ocasiões cívicas, mas também em celebrações e eventos religiosos desse grupo como a "semana das missões mundiais e estaduais" 23 . Ademais, os valores nacionais e patrióticos eram presentes no cotidiano institucional onde as missionárias eram formadas. Segundo Maria Lourdes dos Anjos:

A valorização do civismo, as discussões na sala de aula, na matéria Estudos de Problemas Brasileiros (EPB) e a prática constante do hasteamento do pavilhão nacional estavam tão presentes na instituição que, no início de cada mês, as alunas observavam o quadro para verificar se seus nomes constavam para hastear a bandeira. Uniformizadas, logo cedo estavam perfiladas para saudar o dia com o Hino Nacional Brasileiro. ${ }^{24}$

O modelo de ordem social que parecia ser apontado pelas sociedades coloniais portuguesas e as instituições religiosas batistas brasileiras são sinais consideráveis de um campo discursivo ${ }^{25}$ dentro do qual se construíam sentidos para as representações fotográficas. Assim, em contextos onde "a instrumentação das escolas a serviço dos ideais

${ }^{21}$ TESSADORI, Pietro. O homem novo do fascismo italiano e do estado novo português. Tese de doutorado em História. Instituto Universitário de Lisboa, Universidade Católica Portuguesa/ Universidade de Évora, Lisboa, 2014.

22 MARQUES, 1986, p. 426, Apud THOMAZ, Omar Ribeiro. Ecos do Atlântico Sul. São Paulo: ed. UFRJ/FAPESP, 2002, p.89.

${ }^{23}$ ANJOS, Maria de Lourdes Porfírio Ramos Trindade dos. Educação feminina batista no Nordeste: a ação educacional de Martha Elizabet Heristhon no Seminário de Educadoras cristãs de Recife (1953-1979). Tese de doutorado em Educação. Programa de Pós Graduação em Educação, Universidade Federal de Uberlândia, 2013. p.262.

${ }^{24}$ ANJOS, Maria de Lourdes Porfírio Ramos Trindade dos. Educação feminina batista no Nordeste: a ação educacional de Martha Elizabet Heristhon no Seminário de Educadoras cristãs de Recife (1953-1979). Tese de doutorado em Educação. Programa de Pós Graduação em Educação, Universidade Federal de Uberlândia, 2013. p. 156.

${ }^{25}$ FOUCAULT, Michel. A arquelogia do saber. $5^{\mathrm{a} e d, ~ R i o ~ d e ~ J a n e i r o: ~ F o r e n s e ~ U n i v e r s i t a ́ r i a, 1997 . ~ p . ~} 31$. 
nacionais, religiosos e sociomorais" ${ }^{26}$ eram notórios, é importante atinar para a comunhão simbólica e de práticas culturais que parecia haver dentro daquele universo.

Contatos e aproximações entre as lideranças daquele grupo religioso e autoridades militares que gravitavam na órbita dos governos ditatoriais dos dois países também eram sinalizadas nas páginas do periódico. Por volta de 1968, pastores que representavam importantes lideranças batistas brasileiras adquiriam "bolsas" do governo militar para realizarem cursos de formação na Escola Superior de Guerra (ESG). Em Moçambique, missionários portugueses desse grupo religioso posavam em fotografias, ao lado de militares do alto comando colonial, indicando que essas aproximações não se restringiam apenas ao contexto brasileiro.

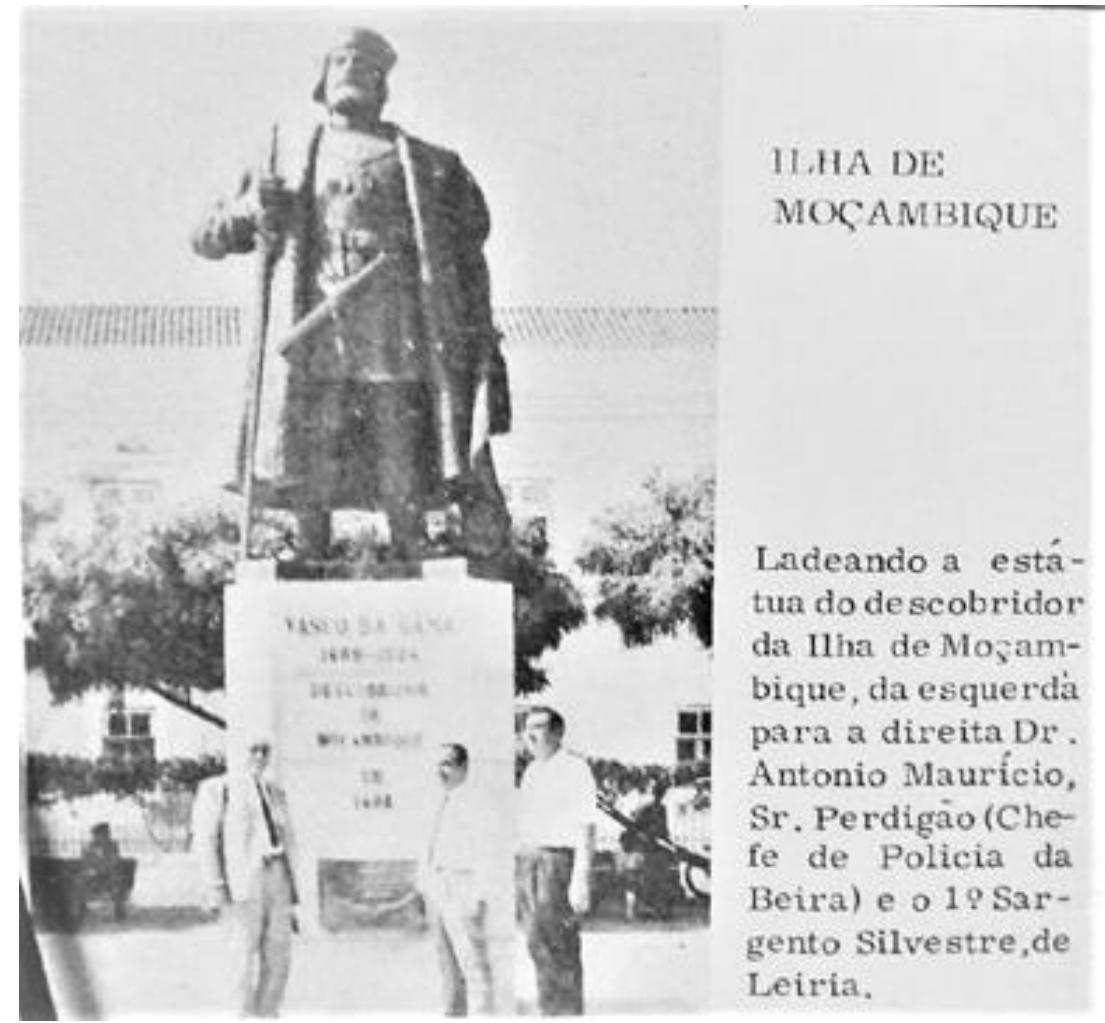

Imagem 4: Estátua do descobridor da Ilha de Moçambique. Revista O Campo é o Mundo, 1968, nº 10, p. 14.

Além das fotografias, havia também textos da revista $O$ Campo é o Mundo que afi rmavam a existência de colaboração dos missionários com as autoridades coloniais portugu esas que lhes concediam a permanência em Moçambique.

Em Angola, outro ponto dos territórios lusófonos africanos, outros números da mesma revista afirmavam que jovens angolanos costumavam ser bem recepcionados pelas

${ }^{26}$ FRAGO, Antônio Viñao; ESCOLANO, Agustin. Currículo, espaço e subjetividade: arquitetura como programa. Tradução: Alfred Veiga Neto, Rio de Janeiro: ed. DPeA, 1998. p.40. 
forças armadas luso-coloniais quando identificavam-se como membros de igrejas batistas ${ }^{27}$ oque, podemos considerar enquanto pistas indicadoras da existência de relações próximas e de cooperação entre batistas e militares no Brasil e no além mar português em período de colonialismo tardio.

Assim, as relações com as autoridades militares brasileiras e portuguesas e a comunhão de princípios e práticas culturais presentes na vida religiosa e nos rituais cívicos das instituições batistas simbolizavam valores como a disciplina e o patriotismo, importantes não apenas para o regime militar brasileiro, como também par a a ditadura salazarista portuguesa. Podemos toma-los como representações e práticas culturais que representavam uma forma de ser e de se colocar socialmente, nos possibilitando suprir um pouco mais a ausência de informações autorias das fotografias pelo conhecimento do provável mundo dos intérpretes.

\section{Os africanos e suas representações: o perfil dos fotografados.}

Se, por um lado, o polo produtor e consumidor das fotografias é parcialmente identificável, por outro, os fotografados também compunham um perfil reconhecível nas páginas da revista. Sem voz e sem autoria dos discursos sobre si próprio, o africano apresentado nas fotografias do periódico era, sem dúvida, um ser humano infantil que, silencioso ou silenciado, aguardava pelo gesto ocidental que lhe faria imergir de um mundo atrasado, selvagem e carente do qual precisava ser resgatado por intermédio do que Edward Said denominou, genericamente, de discursos ocidentais universalizantes que "pressupõem o silêncio, voluntário ou não, do mundo não-europeu. Há incorporação; há inclusão; há domínio direto; há coerção. Mas muito raramente admite-se que o povo colonizado deve ser ouvido e suas ideias conhecidas" 28 .

Essa maneira de construir sentidos na alteridade entre Nós e Eles era continuidade de uma longa história de representações inferiorizantes sobre a África na qual, agora, a partir do reaproveitamento daquelas fotos, o periódico batista se inseria. Colocadas na perspectiva dessa extensa tradição multissecular produtora das vozes que silenciam e inferiorizam o continente africano $^{29}$, tais fotografias não podem ser discutidas se ignorarmos a existência

\footnotetext{
${ }^{27}$ Ver: MOREIRA, Harley Abrantes. Missões Batistas em Angola e Moçambique no Período de Descolonização: apontamentos para uma discussão do discurso da revista O Campo é o Mundo. Sankofa Revista de História da África e de Estudos da Diáspora Africana. Ano VII, n XIII, Julho/2014, p.84.

${ }^{28}$ SAID, Edward. Cultura e Imperialismo. Ed. Companhia das Letras, São Paulo, 2011. p.86.

${ }^{29}$ Essa longa tradição costuma ser mapeada a partir dos relatos de Heródoto na antiguidade, com importantes reforços e recriações no período medieval e moderno, até atingir a era dos imperialismos coloniais do século XIX e XX, quando o discurso científico lhe legitimou e ajudou a criar, para esse conjunto de lendas, mitos, imagens e discursos inferiorizantes, um estatuto de verdade. Essa longa tradição, a respeito da qual
} 
de um conjunto de elaborações preconceituosas e racistas sobre a África correlacionadas à discriminação sofrida por afro-descendentes no Brasil e no mundo, construídas sobretudo na modernidade a partir de distorções, simplificações e generalizações que incidem sobre as populações africanas quando entram no campo de visão da retina colonialista, reforçadora do suposto caráter primitivo e selvagem de povos a serem civilizados ${ }^{30}$.

A partir do século XIX, diversos preconceitos anteriores se articularam com as afirmações de um evolucionismo social, consequente das crenças científicas confirmadoras de estereótipos que, na segunda metade do século $\mathrm{XX}$, a revista ainda reproduzia. Segundo Anderson Ribeiro Oliva, o determinismo racial e todos os conhecimentos racialistas produzidos por saberes científicos do século XIX,

alocaram os africanos nos últimos degraus da evolução das "raças" humanas. Infantis, primitivos, tribais, incapazes de aprender ou evoluir, os africanos deveriam receber, portanto, a benfazeja ajuda europeia por meio das intervenções imperialistas no continente. ${ }^{31}$

Segundo este autor, essa perspectiva teve um efeito norteador sobre as representações elaboradas a respeito dos africanos do século XIX em diante, e apontava para uma inferioridade biológica, mental e espiritual dos povos da África, o que nos leva a aproximá-la de uma leitura diacrônica das fotografias divulgadas pela Revista $O$ Campo é $o$ Mundo na década de sessenta do século $\mathrm{XX}$, quando textos que margeavam as fotos combatiam o relativismo cultural, dialogando com fotografias de pessoas caracterizadas por roupas e adereços não ocidentais, como as peças encontradas na imagem número dois.

Nesse material, as cinco fotografias se acompanhavam de uma legenda com os termos: "islamismo, feiticismo, muçulmanismo, paganismo e animismo". Ao trazer a frase "pessoas que teriam obrigação de saber mais, dizem que os pagãos são melhores do que elas e que sua religião os satisfaz" ${ }^{32}$, o autor parecia se referir aos representantes de um saber

historiadores renomados como o franco-congolês Elikia M'Bokolo empregam o termo “inesgotável repositório de tolices", dialogou com importantes processos históricos como o colonialismo em África e foi acessada para legitimar, por um lado, a desvalorização dos negros e do continente africano e, por outro, as resistências africanas. Ver: M'BOKOLO, E. África Negra. História e civilizações tomo I (até o século XVIII). Ed. EDUFBA e Casa das Áfricas, Salvador e São Paulo, 2009. p.45-53. Ver também: OLIVA, Anderson Ribeiro. A História da África nos Bancos Escolares: Representações e imprecisões na literatura didática. Estudos AfroAsiáticos, ano 25, n³, 2003. p.431-440.

${ }^{30}$ Ver: MUDIMBE, V. A Invenção de África, Gnose, Filosofia e a Ordem do Conhecimento. Ed. Pedago, Mangualde-Portugal \& Ed. Mulemba, Luanda-Angola, 2013, p.76.

${ }^{31}$ OLIVA, Anderson Ribeiro de. Em busca de um diálogo afrocentrado acerca das cosmologias africanas. Fênix - Revista de História e Estudos Culturais, janeiro-junho de 2017, vol.14, ano XIV, nº1. p.261

${ }^{32}$ Biblioteca do Seminário de Educadoras cristãs de Recife. REDAÇÃO, Revista O Campo é o Mundo, 1967, Sua religião lhe satisfaz? Ed. JUERP, nº, p.4. 
especializado, de quem o texto seguia discordando com base em relatos de rituais e práticas culturais de povos considerados infelizes, notadamente os chamados "maometanos da África" que, segundo a revista, faziam grandes cortes na cabeça, estancando o sangue com folhas de jornais.

O autoquestionamento sobre a postura missionária que, supostamente, penetraria nas culturas autóctones, provocando suas transformações através das conversões religiosas, por ignorância dos significados culturais étnicos e por presunção de que sua fé era mais adequada para o bem estar das populações exóticas, era respondido com argumentos de reafirmação dos propósitos missionários. Caberia a esses cristãos "libertar" os nativos dos sofrimentos causados por suas "superstições", seus rituais e práticas que agrediam seus próprios corpos.

A presença desse tipo de texto e do debate que promoviam com os saberes dirigidos aos povos étnicos africanos pode abrir margem para supor que, ao se deparar com as cicatrizes no rosto de um outro negro fotografado na imagem seguinte (número 3), o público leitor da revista pudesse associar os cortes em destaque, em uma de suas faces, às práticas de auto sacrifícios impostas por suas religiões consideradas primitivas. Além dessa interpretação que destacaria o exotismo e a necessidade de intervenção espiritual dos missionários batistas em África, o conjunto de fotografias publicadas pela revista na década de sessenta explorava outros significados e podemos conjecturar ainda, que evocassem alguns passados mais específicos, presentes na memória social do público leitor brasileiro que se conectava a uma comunidade de sentido, gravitando em torno do mundo visual português.

Esses "olhares do império" se verificam nas diferentes cenas imagéticas como a que se passa na primeira fotografia (imagem número um), onde nota-se pessoas supostamente africanas carregando grandes presas de marfim, abrindo aos leitores possibilidades de associação da imagem com a exploração do trabalho escravo para o comércio dessa valiosa matéria prima, recolocando o africano na mesma posição social que ocupou durante mais de três séculos no Brasil escravista. Assim, a fotografia, de modo particular, atualizaria passados aprisionados por suas molduras, dentro de um enquadramento mecânico que lhe conservaria em uma permanência fixa, natural e atemporal, dentro da qual sugeriria que negros africanos são, sempre, sinônimos de escravos.

Não foram apenas escravizados em algum momento do passado. A fotografia participa de um processo de congelamento temporal e essencialização das identidades, acessado de maneiras diferentes, em propósito de variadas finalidades, especialmente 
quando essa fotografia não apresenta uma legenda com a data de sua produção. Transformam-se em objetos meta-temporais, aprisionando nessa mesma categoria aqueles sujeitos históricos nela fotografados que, uma vez captados pelas retinas dos leitores brasileiros, poderiam se encontrar com uma memória social da escravidão que, na época, havia sido oficialmente abolida há cerca de sete décadas.

Essa característica da fotografia, capaz de tornar contemporâneos passado e presente na memória social que conecta seus leitores, já foi apontada por Canabarro, para quem as imagens fotográficas registravam "cenas de um tempo continuum que foram perenizadas no ato fotográfico, podendo ser transportadas para outras temporalidades, mediante uma mistura de passado-presente". 33

Assim, além dos sacrifícios ritualísticos e da infelicidade de seus praticantes, a memória social da escravidão também pode ser imaginada como alvo dos apelos imagéticos da revista e, na terceira fotografia da sequência (imagem três), à esquerda da primeira página, o enquadramento do fotografado pelas lentes do fotógrafo sugere outros questionamentos. Por que aquela preferência em retratar apenas uma das faces daquele rosto negro que ali conservava suas cicatrizes? Por que desprezar quase a totalidade do restante de um corpo de apresentação desnecessária?

Aquele foco realçava as marcas que, conforme sublinhava o texto escrito, poderiam ser a prova dos rituais religiosos "violentos" e "primitivos" dos nativos africanos. Era o conjunto dessas imagens que comunicava algo de dramático na situação de negros machucados por seus ritos religiosos ou escravizados, segundo sugestão da primeira fotografia, onde se destacavam os corpos negros condicionados para a exploração de marfim.

Aquela imagem, onde o marfim derivado da mutilação animal era carregado pelos negros africanos, se continha nas molduras de um enquadramento produtor de esteriotipagens que, nos termos de Stuart Hall, seriam maneiras de se apossar de características simples, vívidas, memoráveis, facilmente compreendidas e amplamente reconhecidas sobre as pessoas para reduzi-las, essencializá-las, naturalizá-las e fixá-las em suas condições de diferentes ${ }^{34}$ que, assim, tornavam-se congelados naquele enquadramento que lhes aprisionava em uma completa e essencial realidade, dotada de passado e presente.

\footnotetext{
${ }^{33}$ CANABARRO, Ivo. Fotografia, história e cultura fotográfica: aproximações. Estudos Ibero-americanos, v.31, 2, 2006. p.25.

${ }^{34}$ Ver: HALL, S. Cultura e representação. Tradução: Daniel Miranda e William Oliveira. Ed. PUC-Rio; Apicuri, Rio de Janeiro, 2016. p.191.
} 
A ausência de legendas, se por um lado nos impede de ter acesso imediato a informações importantes como data, local e autoria da fotografia, por outro pode indicar determinada intenção por parte da revista em se comunicar com o imaginário de suas comunidades religiosas brasileiras, através de uma estereotipagem eficiente em representar um tipo africano escravizado, explorado e carente da intervenção religiosa dos missionários batistas, cuja utilização como mão de obra escrava, central para a produção de diversos estereótipos inferiorizantes, era bem conhecida do universo mental brasileiro acostumado a generalizar a diversidade de sujeitos africanos em torno da imagem do trabalho escravo, deslocando toda a África para um passado, teoricamente "superado", no Brasil, em 1888, com a abolição da escravatura e que resistiria apenas em regiões atrasadas no tempo como as colônias africanas.

Nesse sentido, pode-se supor que a imagem fotográfica de pessoas negras transportando presas de marfim, tenderia a ser vista como um signo, representando algo distinto de si mesmo, nesse caso, a própria vulnerabilidade de pobres africanos explorados e escravizados no passado ou no presente, não cristãos, órfãos de Deus e necessitados do resgate missionário.

Ao analisar essas imagens é preciso considerar, ainda, que quase sempre elas estavam acompanhadas de um texto publicado nas páginas da revista, e com ele compunham uma única peça oferecida ao público leitor. Em 1969, o periódico estampava em suas páginas uma reflexão produzida pelo missionário português Antônio Maurício que acusava seus compatriotas colonizadores "racistas" (sempre os outros, naturalmente) de se internar nos sertões africanos para "arrebanhar homens e mulheres e torna-los animais de carga, contrariando o claro ensinamento de Cristo de que todos somos irmãos." ${ }^{35}$

Segundo seu depoimento, o autor missionário e ex-combatente havia conhecido parte da África aos vinte anos como soldado do exército português na Primeira Guerra Mundial, antes de se converter ao cristianismo batista. Após sua campanha militar repleta de aventuras, se compadeceu de um povo que, admitiu, considerava "hostil" antes de conhecer, mas, depois, teria descoberto que, em suas palavras, estava diante de "almas brancas em corpos negros" e, por isso, resolveu voltar ao continente africano, agora como missionário, para salvar tais "almas."

\footnotetext{
${ }^{35}$ Biblioteca do Seminário de Educadoras cristãs de Recife. REDAÇÃO, Revista O Campo é o Mundo, 1969, África por quê? Ed. JUERP, abril a junho, p.14.
} 
Além de demonstrar a força de uma cultura imperial racista que resistia, mesmo dentro daqueles que pensavam denunciá-la, o texto é também um exemplo de que missionários poderiam agir sob motivações religiosas que lhes diferenciavam dos “colonizadores" propriamente ditos. Ademais, o missionário compadecido não apenas da perdição das almas mas da situação social das populações nativas exploradas, indicava que tal exploração e a "escravização" dos negros africanos (transformados em "animais de carga", segundo o missionário) era uma ideia que circulava nas páginas da revista através de testemunhos de portugueses que, como os de Maurício, aproximavam a África dos brasileiros através de uma imprensa batista que dialogava com aquela política do olhar lusitana, utilizando os mesmos códigos de comunicação que prevaleciam no periódico trimestral.

\section{Considerações Finais}

Considerando que a história é construída com provas, possibilidades, erudição e imaginação ${ }^{36}$, as fotografias sem indicação de autoria presentes na Revista $O$ Campo é $o$ Mundo podem constituir importantes pistas para o trabalho do historiador. Através da linguagem, sujeitos sociais diferentes são mediados e, na relação entre cristãos batistas lusobrasileiros e africanos, a linguagem fotográfica assumiu esse papel onde um Outro colonizado era, então, representado fotograficamente e, assim, "ressignificado junto ao seu cosmos". ${ }^{37}$ Essa construção de sentidos era, na década de 1960, amplamente praticada dentro de um circuito europeu de produção e consumo imagético, sendo provável que, através da intensa comunicação entre batistas portugueses e brasileiros, tal circuito tenha alcançado e envolvido os leitores dessa mídia confessional no Brasil.

Essa política do olhar se fazia conhecida através das representações de um mundo desconhecido, difundindo nos trópicos uma dada maneira de ver a África e os africanos, através das fotografias publicadas pela Revista $O$ Campo é $O$ mundo enquanto material moldado por sua experiência social. Nesse texto, procuramos mostrar que o conteúdo imagético encontrado no periódico parecia funcionar como vetor de comunicação cultural dentro dessa experiência formadora de sentidos e que, mesmo sem as informações autorais necessárias para sua análise, é possível, ao historiador, seguir as pistas que apontem para os espaços de língua portuguesa onde tais imagens circulavam.

\footnotetext{
${ }^{36}$ GUINZBURG, C. Apêndice - Provas e possibilidades. In: O Fio e os Rastros. Cia das Letras, São Paulo, 2014, p.311-335.

${ }^{37}$ BEZERRA, Benedito \& MOREIRA, Harley Abrantes. A operação da Linguagem no movimento de (des) construção da realidade. In: BEZERRA, Benedito Gomes e LUNA, Jairo Nogueira (Orgs). Língua, literatura e ensino: subsídios teóricos aplicados. Recife-PE: ed. EDUPE, 2009. p.25.
} 
Esses espaços foram amplamente partilhados por pastores, missionários (a), instituições, correspondências e periódicos batistas repletos de fotografias, nas quais os africanos eram conhecidos e interpretados segundo os códigos de uma comunidade de sentidos, profusa de estereotipagens e significados que denotavam a hierarquia existente entre o "exótico" mundo africano e o mundo do colonizador, do qual as imagens publicadas pela Revista $O$ Campo é o Mundo queriam participar ao cooperarem com uma construção simbólica que funcionava a serviço de uma cultura colonial portuguesa, fortemente apoiada nas práticas de consumo imagético, alicerces de um imperialismo português.

Data de submissão: 10/05/2021

Data de aceite: 08/12/2021 


\section{Referências Bibliográficas}

ABOUT, Ilsen \& CHÉROUX, Clement. L'histoire par la photographie. Revista Études photographiques, Société Française de Photographie, Paris: nov. n.10, 2001, p.1-20.

ANJOS, Maria de Lourdes Porfírio Ramos Trindade dos. Educação feminina batista no Nordeste: a ação educacional de Martha Elizabet Heristhon no Seminário de Educadoras cristãs de Recife (1953-1979). Tese de Doutorado em Educação. Fculdade de Educação/UFU, Uberlândia, 2013.

BEZERRA, Benedito \& MOREIRA, Harley Abrantes. A operação da Linguagem no movimento de (des) construção da realidade. In: BEZERRA, Benedito Gomes e LUNA, Jairo Nogueira (Orgs). Língua, literatura e ensino: subsídios teóricos aplicados. RecifePE: ed. EDUPE, 2009, p. 25.

BORGES, Maria Eliza Linhares. História e Fotografia. Belo Horizonte-MG: Ed. Autêntica, 2013, p.24-35.

CADIOU, COULOMB, LEMONDE, SANTAMARIA, Como se faz a história? Historiografia, método e pesquisa. Tradução: Giselle Unti, Petrópoles-RJ: ed. Vozes, 2007, p.141-153.

CANABARRO, Ivo. Fotografia, história e cultura fotográfica: aproximações. Estudos Ibero-americanos, v.31, 2, 2006, p.23-39. https://doi.org/10.15448/1980-864X.2005.2.1336.

CANABARRO, Ivo Santos. Fotografa e História: questões teóricas e metodológicas. Revista Visualidades, Goiânia, v.13, n.1, jan-jun 2015, p.98-125.

CARVALHO, Vânia Carneiro de \& LIMA, Solange Ferraz de. Fotografias: usos sociais e historiográficos. In: O historiador e suas fontes. Ed. Contexto, São Paulo, 2009, p.29-60.

CERTEAU, Michel de. A cultura no plural. Campinas-SP: ed. Papirus, 4a. ed., 1995, p.233-234.

CHARTIER, Roger. A História Cultural - entre Práticas e Representações. Rio de Janeiro: ed. Bertran Brasil, 1990, p.17.

CHARTIER, Roger. Leituras e leitores na França do Antigo Regime. São Paulo: ed. Unesp, 2004, p.13-14.

DUBOIS, Philippe. O ato fotográfico e outros ensaios. Campinas: Papirus, 1994, p.25-27.

FOUCAULT, Michel. A arquelogia do saber. 5aed, Rio de Janeiro: Forense Universitária,1997, p.24.

FRAGO, Antônio Viñao; ESCOLANO, Agustin. Currículo, espaço e subjetividade: arquitetura como programa. Tradução: Alfred Veiga Neto, Rio de Janeiro: ed. DPeA, 1998, p.40.

GINZBURG, Carlo. Apêndice - Provas e possibilidades. In: O Fio e os Rastros. São Paulo: Ed. Companhia das Letras, 2014, p.311-338. 
GOMES, Inês Vieira. Imagens de Angola e Moçambique na metrópole. Exposições de fotografias no Palácio Foz (1938-1960). In: O Império da visão: fotografia no contexto colonial português (1860-1960). Lisboa: ed. Edições 70, 2014, p.353-366.

HANNERZ, U. Fluxos, fronteiras, híbridos: palavras-chave da antropologia transnacional. In: Mana, Rio de Janeiro, $\mathrm{n}^{\circ}$ 3, vol. 1, 1997, p.7-39.

HALL, STUART. Cultura e representação. Organização e revisão técnica: Arthur Ituassu; Tradução: Daniel Miranda e William Oliveira. Rio de Janeiro: ed. PUC-Rio/Apicuri, 2016, p.17-30; 161-174.

KOSSOY, Boris. Fotografia e História. São Paulo: ed. Ateliê, 2003, p.19-64.

MARCUSCHI, Luiz Antônio. A construção do imobiliário do mundo e da mente: linguagem, cultura e categorização. In: Cognição, linguagem e práticas interacionais. Rio de Janeiro: ed. Lucerna, 2007, p.124-145.

MAUAD, Ana Maria. Na mira do olhar: um exercício de análise da fotografia nas revistas ilustradas cariocas, na primeira metade do século XX. Anais do Museu Paulista. São Paulo: n.1, v.13, jan.-jun. 2005, p.133-174.

MOREIRA, Harley Abrantes. As Fotografias das Missões Batistas Brasileiras na África Lusófona em Período de Descolonização: Representações de um Projeto Missionário. In: Experiências Missionárias - Trajetórias coloniais e pós-coloniais em África. Africana Studia - Revista Internacional de Estudos Africanos. Porto: ed. Centro de Estudos Africanos da Universidade do Porto, n²3, 2014, p.46.

MOREIRA, Harley Abrantes. Batistas brasileiros em Moçambique: cultura, política e missionarismo no colonialismo tardio e no pós-independência. In: MOREIRA, Harley Abrantes; MOURA, Carlos André Silva de; SILVA, Eliane Moura da (Orgs.). Missões, religião e cultura: estudos de História entre os séculos XVIII e XX. Curitiba-PA: ed. Prismas, 2017, p.348-351.

MOREIRA, Harley Abrantes. Missões Batistas em Angola e Moçambique no Período de Descolonização: apontamentos para uma discussão do discurso da revista O Campo é o Mundo. Sankofa - Revista de História da África e de Estudos da Diáspora Africana. São Paulo: Ano VII, n XIII, Julho/2014, p.4.

MOREIRA, Harley Abrantes. “Onde há desespero, a esperança é importante"? Uma história da expansão do cristianismo batista em Moçambique (1950-1992). Tese de Doutorado em História cultural, Instituto de Filosofia e Ciências Humanas, UNICAMP, Campinas, 2019.

MUDIMBE, V, Y. A Invenção de África, Gnose, Filosofia e a Ordem do Conhecimento. Luanda-Angola: ed. Pedago/Mangualde, 2013, p.76.

OLIVA, Anderson Ribeiro. A História da África nos Bancos Escolares: Representações e imprecisões na literatura didática. Rio de Janeiro: Estudos Afro-Asiáticos, ano 25, n³, 2003, p. 431-440. 
OLIVA, Anderson Ribeiro. Em busca de um diálogo afrocentrado acerca das cosmologias africanas. Fênix - Revista de História e Estudos Culturais, janeiro-junho de 2017, vol.14, ano XIV, nº 1, p.261.

ORLANDI, Eni P. Análise de Discurso. Campinas: ed. Pontes, 2005, p.9-35.

RYAN, J. Introdução. Fotografia colonial. In: VICENTE, F. O Império da visão: fotografia no contexto colonial português (1860-1960). Lisboa: ed. Edições 70, 2014, p.31-44.

ROCHA, C. O Brasil na nova cartografia global da religião. Revista Religião e Sociedade, Rio de Janeiro: vol.34, $\mathrm{n}^{\circ} 1$, junho de 2014, p.22.

SAID, Edward. Cultura e Imperialismo. Ed. Companhia das Letras, São Paulo, 2011, p.86;305.

SANTANA, Noeme. Olhares britânicos: visualizar Lourenço Marques na ótica de $\mathbf{J}$ and $\mathbf{M}$ Lazarus, (1899-1908). In: VICENTE, Filipa Lowndes. O Império da visão: fotografia no contexto colonial português (1860-1960). Lisboa: ed. Edições 70, 2014, p.211-222.

SILVA, Cristiane Nascimento da. "Viver a fé em Moçambique": as relações entre a FRELIMO e as confissões religiosas (1962-1982). Tese de doutorado em História Social, Instituto de História, UFF, Niterói, 2017.

SILVA, Cristina Nogueira da. O registro da diferença: fotografia e classificação jurídica das populações coloniais (Moçambique, primeira metade do século XX). In: VICENTE, F. O Império da visão: fotografia no contexto colonial português (1860-1960). Lisboa: ed. Edições 70, 2014, p.67-84.

SILVA, Paulo Julião da. "E Jesus foi vitorioso. Aleluia...E a resposta a essa batalha do céu foi 31 de março de 1964" - O alinhamento protestante ao golpe militar. In: MOURA, Carlos André S. de; SILVA, Eliane Moura da; SANTOS, Mario R. dos; SILVA, Paulo Julião da (Orgs.). Religião, Cultura e Política no Brasil: Perspectivas históricas. Campinas: ed. IFCH/UNICAMP, 2011, p.109-132.

SILVA, Paulo Julião da. O Anticomunismo Protestante e o Alinhamento ao Golpe Militar. Curitiba: ed. Prismas, 2014, p.138-152.

TESSADORI, Pietro. O homem novo do fascismo italiano e do estado novo português. Instituto Universitário de Lisboa. Tese de doutorado em História. Universidade Católica Portuguesa, Universidade de Évora, Lisboa, 2014.

THOMAZ, O. R. Ecos do Atlântico Sul. São Paulo: ed. UFRJ/FAPESP, 2002, p.89.

VARGAFTIG, Nadia. Para ver, para vender: o papel da imagem fotográfica nas exposições coloniais portuguesas (1929-1940). In: VICENTE, Filipa Lowndes. O império da visão: fotografia no contexto colonial português (1860-1960). Lisboa: ed. Edições 70, 2014, p.343-352.

VICENTE, F. O Império da visão: histórias de um livro. In: O Império da visão: fotografia no contexto colonial português (1860-1960). Lisboa: ed. Edições 70, 2014, p.11-30. 
WALKER, John Frederick. Ivory's Ghosts: The White Gold of History and the Fate of Elephants. New York: ed. Grove Atlantic (Edição Kindle), 2009, location 108-403.

ZONTA, Diego. "Moçambique" no século XIX: do comércio de escravos ao comércio legítimo. Revista Dimensões, Vitória-ES: vol. 28, 2012.

\section{Fontes Documentais}

Acto Colonial, Decreto-Lei $\mathrm{n}^{\circ} 18570$ de 8 de Julho de 1530. Disponível em: https://dre.pt/pesquisa/-/search/224055/details/maximized. Consultado em: 11 de setembro de 2020 .

BOORNE, Antônio. Revista O Campo é o Mundo, 1966. E a África?, ed. JUERP, no 4, p.4 e 7. Localizada na Biblioteca do Seminário de Educadoras Cristãs (SEC), Recife-PE e Biblioteca do Instituto Batista de Educadoras Cristãs (IBER), Rio de Janeiro-RJ.

GONÇALVES, José Leovegildo Caetano. Revista O Campo é o Mundo, 1968. Minha visita ao Brasil. Ed. JUERP, nº10, p.5. Idem.

MAURÍCIO, Antônio. Revista O Campo é o Mundo, 1969, África por quê?, ed. JUERP, abril a junho, p.14. Idem.

MAURÍCIO, Antônio. Revista O Campo é o Mundo, 1969. Evangelizar Portugal é evangelizar o Brasil, ed. JUERP, outubro-dezembro, p,9. Idem.

REDAÇÃO. Revista O Campo é o Mundo, 1966, Traços históricos do trabalho batista em Portugal, ed. JUERP, n³, p.10. Idem.

REDAÇÃO. Revista O Campo é o Mundo, 1967, O clamor de Coimbra, ed. JUERP, nº 8 , p.12-13. Idem.

REDAÇÃO. Revista O Campo é o Mundo, 1968. Fotos que Falam, ed. JUERP, nº 10, p.14. Idem.

REDAÇÃO. Revista O Campo é o Mundo, 1972. Notícias da África, Idem, p.33-35. Idem.

REDAÇÃO. Revista O Campo é o Mundo, 1973, Notícias da África. Idem, Rio de Janeiro, jan/fev/mar, p.9. Idem.

SMITH, Oswal J. Revista O Campo é o Mundo, 1967, “Sua Religião lhe satisfaz?”, Idem, $\mathrm{n}^{\circ} 8$, p.4. Idem. 